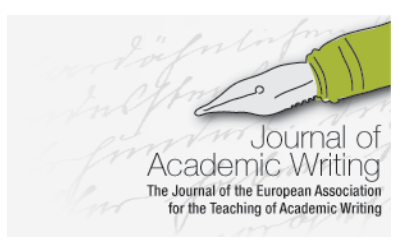

Journal of Academic Writing

Vol. 10 No 1 WINTER 2020, pages 203-212 https://doi.org/10.18552/joaw.v10i1.612

\title{
"The Course Was Not Only for the Semester but Also for Life": Scaffolding Summary Writing for EFL Students Across Academic Disciplines
}

\author{
Carina Sjöberg-Hawke \\ Chalmers University of Technology, Sweden
}

\begin{abstract}
It can be a challenge for a university teacher to arrange the teaching of written tasks so that weak foreign language students with differing disciplinary backgrounds can develop their written communication skills. The difficulty is to avoid the focus from becoming just language proficiency. In one course at a technical university in Sweden, three written summaries are scaffolded to address such a challenge. The purpose of this teaching practice paper is to show how employing a specific strategy of repetition facilitates the writing skill development in lowlevel English language multidisciplinary students. The repeated features are the genre of the task, the writing process used and the occurrences of teacher response. They are organised along a specific learning path so as to encourage the students to build on the knowledge gained in each iteration, between tasks and potentially beyond the course. The paper describes the journey the students take writing the three summaries, working on fulfilling criteria concerned with aspects such as content organisation, coherence and cohesion, and limited grammar errors. A brief analysis of excerpts from one case student's first and third summaries is included. It is suggested that while the scaffolding can remain the same, the material could be replaced to suit other skills and language level needs.
\end{abstract}

\section{Introduction}

For many foreign language (FL) writers, "constructing the subject matter collides with the skills of using the foreign language for coding information" (Ventola, 1996, p. 161). The weaker the FL writer's language level, the more difficult it can be for them to work with more than one writing element in that language. Some students may seek support in courses and language applications, the latter of which is usually focused on language proficiency (Heil et al., 2016). Although language proficiency is an important part of clear written communication, other aspects like those of content organisation and cohesion, are also important (Swales \& Feak, 2004). FL writers in this type of education need instruction which incorporates language proficiency into a wider range of written skills, and where the written tasks have carefully designed scaffolding to facilitate skill development.

The term scaffolding in teaching is often misinterpreted. Benko (2012) and Brownfield and Wilkinson (2018) establish that it is not just another word for support or guidance, as a number of professionals sometimes signal. Although these are relevant words, the term encompasses much more: from interactions between students and teachers to shared understanding of task goals, from material usage and instructional methods to the level and type of teacher response provided, and significantly, the inclusion of responsibility release from teacher to learner, encouraging a student to complete a task independently. The latter is particularly important in education, where the aim tends to be to prepare students to use what they learn on one course in other courses and even beyond studies, or in other words, to transfer the knowledge gained from one context to another. 
Facilitating successful transfer of learning demands careful scaffolding of learning activities. The design needs to make such an impact on a learner that they can later recognise the skill or knowledge as relevant for their current context. This might happen automatically due to the similarity of the task (reflexive transfer) or through a deliberate search for a connection (mindful transfer), i.e. the learner recognises the relevance of the knowledge gained previously for this situation even though the context is quite different (Perkins \& Salomon, 1992). However, with learners needing to manage essential features like sentence and paragraph structure, vocabulary choice and a line of argument, moving between the different settings, like between genres and/or publishing mediums, might affect how well the learning transfer happens (Anson \& Moore, 2016). Still, students need to produce many skilfully written assignments to demonstrate their knowledge and present their work both in courses and later in the workplace. Therefore, it can be logical not only to scaffold writing tasks to facilitate writing skill development but also to facilitate potential writing transfer between tasks. However, add to the equation the elements of foreign language and different language levels, and scaffolding writing tasks becomes a more significant challenge.

At a technical university in Sweden, there is an English course that has endeavoured to address this challenge of scaffolding writing for English as a foreign language (EFL) students across academic disciplines. This paper aims to show that despite many FL students having a low language level and being students of different disciplines, the specific scaffolding of three written summaries, utilising a strategy of repetition, gives them the opportunity to develop and strengthen multiple aspects of their writing skills, not only language proficiency. Additionally, some understanding that transfer can occur between these activities to other contexts is fostered. The contents of this paper are: first, contextual details of the course and its participants; then, a description of the three summaries' scaffolding design; thirdly, an examination of the writing journey the students take, using one student's example to illustrate how the scaffolding can impact a student's writing progress; and finally, a conclusion summarising what can be learned from this scaffolding design.

\section{The Course and the Students}

As some courses and almost all master's programmes at the Swedish university are conducted in English, extra language support is needed for EFL students. A number of optional English language and communication courses are offered. One is more preparatory than others in relation to academic communication skills. It is a 7.5-credit (in the European credit transfer and accumulation system) course (equivalent to 200 hours study running over a sixteen-week term) for low-level English learners. The course aims to support these students in their studies in English by strengthening their spoken and written communication skills. The intended learning outcomes (ILOs) of the course relevant to this paper are:

After completion of the course, a student should be able to:

1. express himself/herself clearly in ... writing in prepared situations,

2. select, structure and present material ... to a non-specialist audience in a clear and effective manner,

3. understand, summarise and reformulate the main content of oral presentations and lectures in ... writing

Presenting material in each assignment to a non-specialist audience, as the second ILO indicates, helps the students reach across the different disciplinary backgrounds that they have (their individual fields can range from biology to architecture to electrical engineering). Additionally, working with a specific audience in mind, the students can push their language and structure skill levels. The language level of the students tends to be basic to intermediate, equivalent to the Common European Framework of Reference for Languages' (CEFR's) A2 and B1 levels, meaning that the students are comfortable speaking and writing about familiar topics but do so in limited detail, and do not always use appropriate structure or keep the audience in mind (Council of Europe, 2020). 


\section{The Scaffolding Design}

With context established, the next section of the paper describes the key components of the scaffolding design: the pedagogical strategy applied, the choice of genre, interrelated written and oral tasks, and an overview of the learning path.

\section{A strategy of repetition}

Repetition is a necessary component of teaching a skill because for a learner to perform a skill with minimal conscious effort and support, the relevant actions and knowledge need repeating, i.e. practising (Felder \& Brent, 2016, p. 71). For developing writing skills, this can involve students producing a considerable amount of written work. For some teachers, this could mean applying a process-oriented approach, using the steps pre-writing, writing, reviewing, and revising, leading to drafts that increasingly display the requirements of a particular genre more successfully. Here the repetition relates to the revision of one text. However, genre repetition is another possible tool. It can allow for a focus on writing skills rather than having differing genre conventions or the perfecting of a text dominate the learning, something which might overwhelm weaker language students who only need to develop aspects such as basic coherence and cohesion. However, there would still be an important iterative element in the composition process: taking notes, selecting information, planning the text, writing, editing and proofreading.

Repetition as a teaching strategy may also come in the form of specific practice exercises, like for grammar or paragraph construction. Alternatively, it might be visible as recurring items through a course, like teacher response. Depending on a student's performance, a teacher either provides new relevant knowledge or reminds (repeats) relevant knowledge. The teacher needs to be able to adjust their response according to the student outcome. Brownfield and Wilkinson (2018, p. 187) call this kind of flexible response "contingent responsiveness"; a teacher regularly provides response but on various aspects of the skill at various stages of the learning activities. In the scaffolding in question, teacher response occurs after each text is submitted.

\section{The genre}

Each written text is a summary. The summary genre can be useful with a low-level language and multidisciplinary group as it tends not to be a genre specific to any particular discipline (Björk \& Räisänen, 1997), meaning that, as mentioned, writing skill focus can be on structure and language and not on specific genre conventions. Typical components of academic text (spoken or written) such as a clear message managed by the three-part structure (introduction, body and conclusion), ideas divided logically into paragraphs, the use of non-ambiguous words, and a lack of language errors can be strengthened and developed. Since much academic work involves referring to and summarising sources, a written summary task is also a pragmatic choice.

\section{Interrelated written and oral tasks}

It is important to note that the oral tasks on the course are also summaries. Although this paper is concerned with the three written summaries, it is necessary to briefly mention the spoken summaries because the teaching and learning of the speaking and writing skills overlap on the course. Both the written and the oral summaries tackle aspects of content, structure and language, which often lead to highlighting the differences between spoken and written language. More significantly, two of the oral summaries are the sources of content for the written summaries (indicated in ILO 3 earlier). This detail is provided in Table 1 below, as well as the content type of each oral and written summary, and the order in which each task appears in relation to each other. 
Table 1

The Oral and Written Summaries: What They Summarise, the Order in the Course and the Length of Each

Oral summary of

1. a non-discipline-specific talk (3 min)

3. a lecture (same as point 2) from disciplinespecific course (4-5 min)

4. a discipline-specific article (4-6 min)

6. a discipline-specific lecture, project, another article or other (5 min)

\section{Written summary of}

2. a lecture from discipline-specific course occurring in parallel (300-400 words, written at home)

5. a peer's third presentation (point 4) (250 words, written at home)

7. a peer's fourth presentation (point 6) (300 words, written in class directly after presentation, time-limit: $60 \mathrm{~min}$ )

Table 1 also reveals that the students have to communicate on topics with which they are not entirely familiar, helping them go beyond their current speaking and writing comfort levels (A2/B1, as indicated earlier). The topic of the first written summary is within their discipline but should be from a recent lecture and thus is still quite unfamiliar content to them. The second and third written summaries are about their peers' presentations, which are likely to be about a different discipline (depending on the variation of the students' backgrounds), and thus also use unfamiliar content. For all three written summaries, the students must summarise the content of what they have listened to for a non-specialist audience (their peers and the teacher). The quality of content is of course reliant on the quality of the presentation, but the FL writers have the opportunity to ask follow-up questions for clarification of details.

\section{The learning path}

As mentioned in the introduction, scaffolding is much more than just synonymous with "support" or "guidance". The scaffolding of the three written summaries is no exception. Figure 1 illustrates the process and activities involved in this particular design..

\section{Figure 1}

The Learning Path of the Scaffolding of the Three Written Texts (T1, T2 and T3).

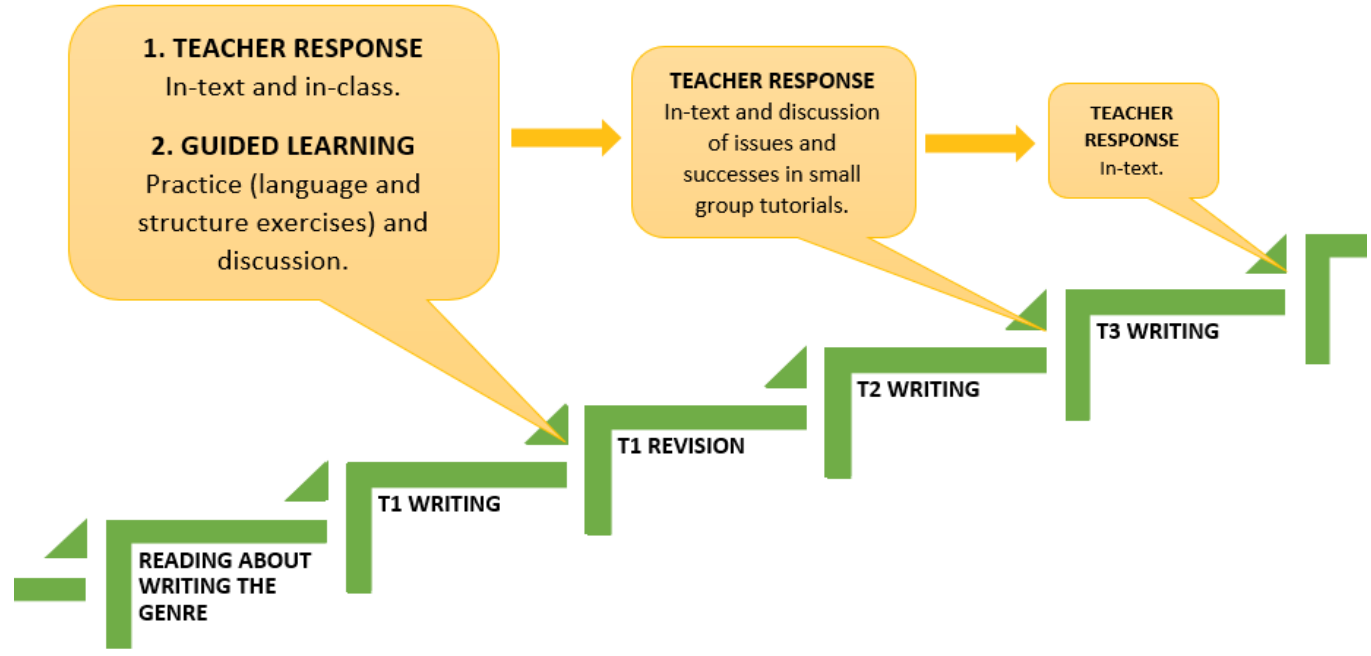


The student activities are highlighted by the green stairs and the sequenced teacher interventions in the orange bubbles. The stairs upward indicate that the students have a goal: to produce continually stronger texts throughout the course. But as can be seen in Figure 1, the stairs continue beyond the feedback for the third text (T3) to emphasise the idea that the skills and the development of them will continue beyond the course. Teacher intervention occurs after each text, but at a reduced quantity each time, so as to release responsibility to the students and foster the possibility of transfer of writing skills between the tasks. Teacher intervention includes in-text and in-class feedback by the teacher as well as guided practice in the first instance.

Brownfield and Wilkinson (2018, p. 187) state that to understand the impact of scaffolding on student learning, details of that gradual release of responsibility, of the above interactions between teachers and students, and of the contingent support need to be examined together with student outcome data. Therefore, in the following section, the journey the students take along the learning path, as visualised in Figure 1 above, is clarified and discussed in detail, and one case student's written summary one (WS1) and written summary three (WS3) are used to illustrate how the scaffolding can impact a student's writing progress (student gave permission to use their work).

\section{The Students' Journey}

The students do not have lectures before writing WS1, but they are recommended to read and use two documents in preparation: a hand-out with summary tips and exercises with links to several online materials, and an extract from the chapter 'What Characterizes a Good Summary' in Björk and Räisänen's book Academic Writing: A University Writing Course (1997, pp. 122-127). The students should also read the assignment instructions for WS1 carefully, which explain that: the text source should be mentioned, the main idea introduced, the student's own words used, formal style is expected, and the text should be self-contained and objective. The students should also view the criteria specific to the final written summary (see Appendix), which indicate what writing skill elements they will be working on during the course.

After WS1 submission, the teacher makes comments in-text on aspects of structure, like introduction, conclusion and paragraph organisation; language, like register, grammar and use of key terms; and content, like source referral and idea progression. With little instruction at this point in the course, some students produce quite informal texts with a number of grammar and paragraphing issues, like the student example below (Figure 2).

\section{Figure 2}

An Excerpt from the Case Student's WS1 (of a Lecture within Their Discipline).

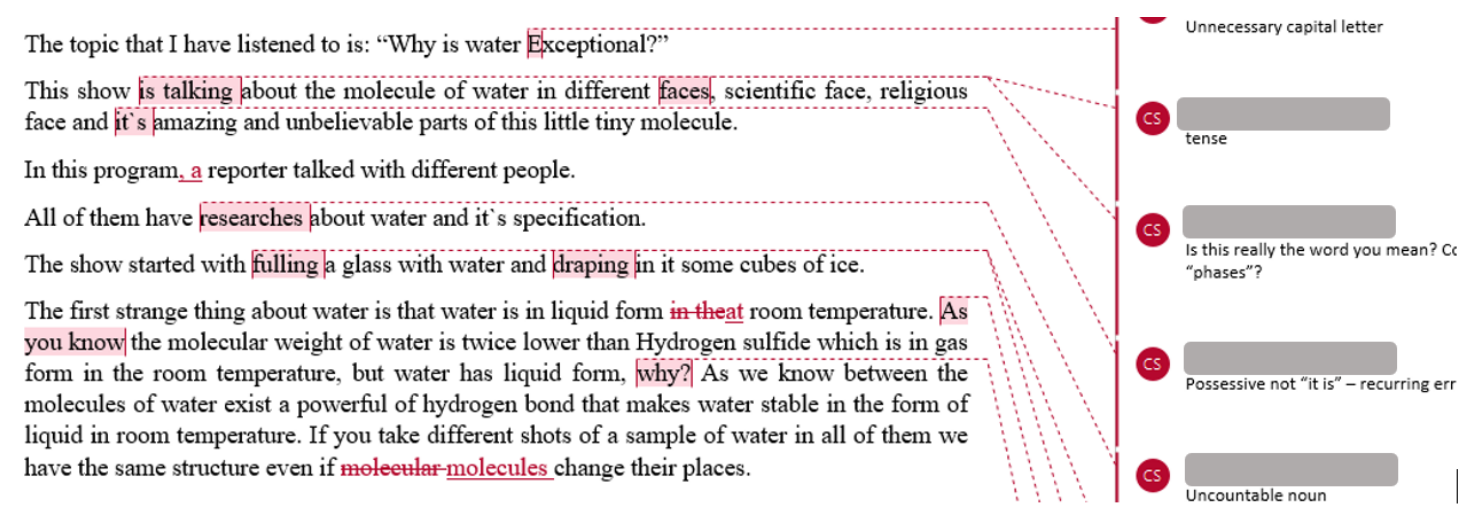

In this example, the student's overall message is conveyed but text construction and language usage are problematic. The order of the information is not logical, and in fact, the text that follows beyond this excerpt defines water, which does not seem logical after discussing bonds. There is an attempt at paragraphing, but the formatting, which is list-like in places, is not 
appropriate for formal writing. Cohesion is also quite limited between sentences. The informal text style continues with the use of vague words, like "show" and "thing", contractions, and direct address, such as "why?" and "as you know". Grammar errors relate to tense, nouns and word forms. Despite this being an early stage of the learning path with the student only having written one summary and had little instruction, in-text comments are kept quite minimal, focusing on grammar and structural issues (as can be seen in Figure 2). More details relating to the feedback are provided in the class time that follows.

Class involves two lectures with workshops. The lectures involve highlighting key and incommon issues contained in the students' texts concerning content, structure and language. There is also discussion about writing a summary, recalling the content of the earlier informational resources, and discussion about the difference between written versus spoken language.

In workshop one, students are given a handout containing two tasks. The first involves helping the students discuss the teacher's marking abbreviations in order to identify the types of errors they make. The second task involves them working in pairs to identify and fix errors in example sentences selected from previous students' work. Combined, these tasks aim to help students understand their own grammar errors in their WS1 and be somewhat prepared to address them when they revise their text.

Workshop two focuses on coherence and cohesion at clause, sentence and paragraph levels. There is a short lecture highlighting the basics of paragraph structure, coherence and cohesion followed by a handout with the following tasks, which the students implement first on their own, but then compare, discuss and justify in pairs: divide a text into paragraphs, arrange given sentences to produce an organised paragraph, and fill in provided gaps with appropriate linking words/phrases.

Following the two workshops, the students revise WS1, applying the knowledge provided in feedback, class instruction and discussion. The revision gives them the chance to examine their specific language and structural errors and decide how to address them. Interactions between teachers and students tend to be quite frequent at this stage as many students email the teachers for advice relating to their structural errors. The majority of students make constructive progress at this stage.

Written summary two (WS2), next, allows the students to build on knowledge and skill awareness gained from the previous activities to improve upon what they have previously produced. Teacher response follows again, but this time there is no classroom instruction. Instead, a tutorial session with the teacher and the student's assigned peer ensues, discussing the successes and errors of that summary and what to consider moving forward into WS3. The students are also directed to utilise the university's online writing guide and grammar tool for further practice and support. Revision is not expected to be submitted this time. Instead they are encouraged to do so for themselves and if they have specific questions around it, to contact the teacher (further responsibility release).

Although the students target a final summary on the learning path they are on, and naturally see this as an opportunity to produce their best course written summary, the scaffolding of the three summaries does not actually stop at the production of WS3. Even if the student fulfils the assignment criteria, part of this scaffolding is about fostering the understanding that the knowledge and skills follow them beyond the course. Therefore, the students also receive constructive teacher feedback within their WS3, with an emphasis on what to consider with any future writing tasks. With this final text, the students usually succeed in producing fewer language errors, more skilful paragraphs and sentences, as well as the more standard threepart structure compared to the previous ones. Figure 3 shows the case student's WS3, which shows improvement from the previous assignments. 


\section{Figure 3}

The Case Student's WS3 (of a Peer's Presentation)

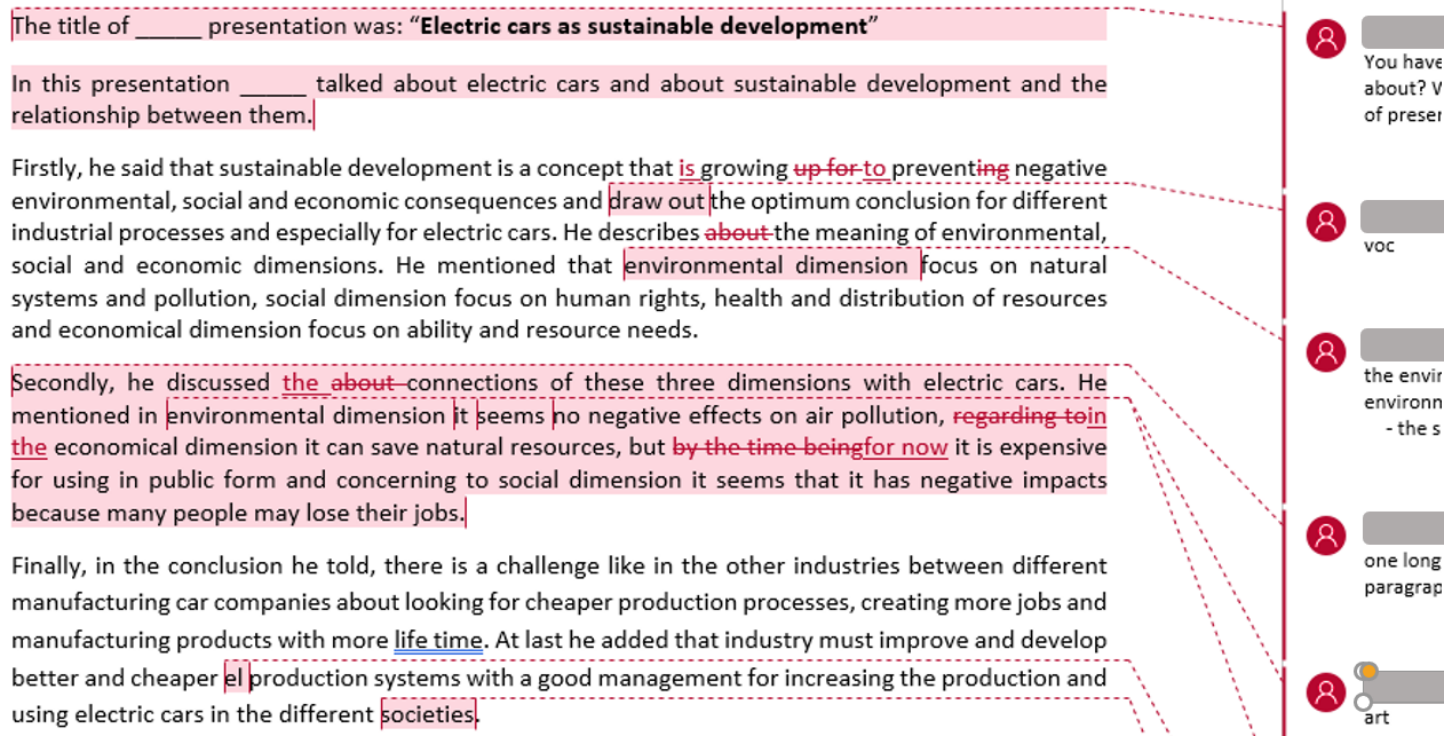

Cohesion is still quite limited, using "he said", "he mentioned", "he describes" to refer to what the peer said rather than connecting the ideas. There are still difficulties with introducing and concluding; the student forgets to introduce the fact that this is a text summarising a particular presentation but rather gives presentation details directly. The close is signalled, but it is the presenter's conclusion rather than the writer's summary conclusion. However, it still fulfils the criteria with a clear beginning, middle and end. The text is also less interrupted by language and structural issues, and the content is in a fairly logical order and has fairly logical paragraph division too (though paragraph composition needs further development). Additionally, the student has now produced a text which is more appropriate to written language than spoken.

In summary, the outcome of this case student's WS1 and WS3 demonstrates that some level of development occurs in the course through following the various student and teacher stages and components of the specifically designed learning path, including: writing three summaries; having practice and discussion opportunities in relation to language and structure issues; and regularly receiving teacher response but at progressively reduced amounts. The student needs to continue the development of their writing skills but has had the opportunity to explore aspects of writing skills relevant for other courses, future studies and beyond.

\section{Conclusion}

The key details of the written summaries' scaffolding are the repeated genre and contingent support. Though circumstances such as topic and text length differ each time, each summary still has the same purpose and audience. This allows the students to focus on their writing skills of content organisation, coherence and cohesion, and even language proficiency, rather than genre differences. The students receive response from the teacher about various aspects of writing at various stages, relating to the content, structure and language (based on criteria), receiving more response from the teacher earlier in the process than later, and addressing the issues raised by the teacher through practice exercises, a revision of WS1 and writing more summaries.

All students who take this language and communication course develop their writing skills to some extent. Just like the case student, they may, by WS3, produce improved paragraphs; fewer language errors; better text introductions, bodies and conclusions; clearer messages and/or a better progression of ideas in comparison to WS1. The students will need to apply these aspects of writing in other assignments at the university. The capabilities of the student 
writers at the start of the course and the type of learners and proactive nature involved likely affect whether the students make great strides or small steps.

Either way, anonymous student evaluation of the course is always positive and underlines the fact that the strategy is working: "Peer system worked well"; "Helpful/good feedback from teacher"; "Nice to have motivating comments". Importantly, one student even declared that "the course was not only for the semester, but also for life" suggesting that as part of the course, the scaffolding of the assignments had a role to play in fostering an understanding that transfer of knowledge can occur. The student's comment suggests potential for mindful transfer (deliberate search for connections). Maybe successful transfer can be said to have transpired between writing tasks based on the progress made, whether large or small, but whether transfer beyond the course, whether reflexive or mindful, occurs is not known. A study of several students' three summaries from the course would need to be conducted to more comprehensively understand the impact of this scaffolding in relation to transfer of learning.

In conclusion, this article set out to show how the key ingredients of the scaffolding of three writing assignments - genre repetition, recurring but gradually reduced teacher response and a specified learning path - foster writing skill development in FL writers. The benefits of this approach for a wide variety of writers are seen in the example course participants' low language level and different disciplines. The students are not overwhelmed with constructing subject matter while simultaneously trying to package the information in a foreign language. The scaffolding design allows for multiple aspects of writing to be worked with (one genre focus, language proficiency, text structure, coherence and cohesion, disciplinary knowledge, and audience) going beyond a traditional language proficiency course. The design is flexible too. The material could be replaced to suit other language levels and skill needs, or a different genre could be used, and other language and structure exercises applied. But the scaffolded arrangement of the learning path's components should remain the same.

\section{Acknowledgements}

The author would like to thank colleagues and the anonymous reviewers for their encouragement and constructive comments. 


\section{References}

Anson, C. M., \& Moore, J. L. (Eds.). (2016). Critical transitions: Writing and the question of transfer. The WAC Clearinghouse/University Press of Colorado. https://doi.org/10.37514/PER-B.2016.0797

Benko, S. L. (2012). Scaffolding: An ongoing process to support adolescent writing development. Journal of Adolescent \& Adult Literacy, 56(4), 291-300. https://doi.org/10.1002/JAAL.00142

Björk, L., \& Räisänen, C. (1997). Academic writing: A university course. Studentlitteratur.

Brownfield, K., \& Wilkinson, I. A. (2018). Examining the impact of scaffolding on literacy and learning: A critical examination of research and guidelines to advance inquiry. International Journal of Educational Research, 90, 177-190. https://doi.org/10.1016/j.ijer.2018.01.004

Council of Europe. (2020). Self-assessment grid - table 2 (CEFR 3.3): Common reference levels - English. Common European Framework of Reference for Languages. https://rm.coe.int/CoERMPublicCommonSearchServices/DisplayDCTMContent?docu $\underline{\text { mentld}=090000168045 b b 52}$

Felder, R. M., \& Brent, R. (2016). Teaching and learning STEM: A practical guide. John Wiley \& Sons.

Heil, C. R., Wu, J. S., Lee, J. J., \& Schmidt, T. (2016). A review of mobile language learning applications: Trends, challenges, and opportunities. The EuroCALL Review, 24(2), 3250. https://doi.org/10.4995/eurocall.2016.6402

Perkins, D. N., \& Salomon, G. (1992). Transfer of learning. International Encyclopedia of Education (2nd ed., pp. 6452-6457). Pergamon Press.

Swales, J. M. \& Feak, C. B. (2004). Academic writing for graduate students: Essential tasks and skills. (2nd ed.) The University of Michigan Press.

Ventola, E. (1996). Packing and unpacking of information in academic texts. In E. Ventola \& A. Mauranen (Eds.), Academic writing: Intercultural and textual issues (Vol. 41, pp.153194). John Benjamins Publishing Company. 


\section{Appendix}

Criteria for the third (final) written summary (WS3):

Pass: The text covers most of the main ideas and main points of one of the fellow student's oral presentations. The text is fairly easy to read. There maybe a few grammar mistakes but overall it is possible to read and understand the document. There is a general structure, meaning that there is an opening, a main body and a close, which makes the document more or less self-sufficient.

Fail: Language mistakes cause problems and confusion to such extent that it is difficult for a reader to understand the text. There is no obvious structure to the text, i.e. general text-type features of a summary (e.g. introduction, body and conclusion) are missing. 